\title{
O APOCALIPSE DA PECUÁRIA: UMA SÍNTESE CALEIDOSCÓPICA DOS RISCOS E POSSIBILIDADES DE MUDANÇA
}

\author{
The Animal Agriculture Apocalypse: a kaleidoscopic synthesis of the risks and \\ possibilities of change
}

Recebido:07.07.2018 | Aceito: 20.07.2018

\begin{abstract}
Paula Brïgger
Bióloga, Doutora em Sociedade e Meio Ambiente, Professora Titular do Departamento de Ecologia e Zoologia/UFSC. Coordenadora do Observatório de Justiça Ecológica da Universidade Federal de Santa Catarina (OJE/UFSC). E-mail: paula.brugger@ufsc.br, Lattes: http:/ / lattes.cnpq.br/4806860050033670
\end{abstract}

\begin{abstract}
Resumo
Existe atualmente um sólido conjunto de evidências acerca da insustentabilidade de uma das mais onipresentes indústrias do planeta: a pecuária. Este artigo, baseado em pesquisa bibliográfica e documental, oferece um panorama dos impactos negativos oriundos desse setor produtivo, abordando principalmente seus aspectos ambientais e éticos por meio de dados em nível nacional e mundial. O objetivo é mostrar como o especismo e a racionalidade instrumental, dominantes em nossa cultura, encontram-se no cerne dos problemas citados e quais são seus principais desdobramentos e consequências. O artigo propõe um novo fundamento ético/epistemológico baseado no abolicionismo animal e na revisão crítica do paradigma hegemônico, destacando a importância de um olhar sistêmico e transdisciplinar como maneira privilegiada de compreender a inextricável ligação entre tais traços culturais e diversas categorias de riscos. Por fim, afirma-se a importância de uma educação e de uma legislação abolicionistas como maneiras privilegiadas de transcender esse cenário, sendo a educação formal a via mais poderosa.
\end{abstract}

Palavras-chave: Educação; Impactos da Pecuária; Legislação; Transdisciplinaridade; Veganismo.

\begin{abstract}
There is currently a robust body of evidence about the unsustainability of one of the most ubiquitous industries on the planet: animal agriculture. This article provides an overview of the negative impacts of this productive sector, focusing mainly on its environmental and ethical aspects, through national and global data. The objective of this bibliographical and documentary research is to show how speciesism and instrumental rationality, dominant in our culture, are at the heart of the problems cited and what are their main unfoldings and consequences. It is proposed a new ethical/epistemological foundation, based on animal abolitionism and a
\end{abstract}


critical revision of the hegemonic paradigm. It is also highlighted the importance of a systemic and transdisciplinary view as a privileged way of understanding the inextricable connection between these cultural traits and different categories of risks. Finally, the article emphasizes the importance of both an abolitionist education and legislation as privileged ways of transcending this scenario, with formal education being the most powerful way.

KeYwords: Education; Impacts of Livestock; Legislation; Transdisciplinarity; Veganism.

SuMÁrio: Introdução; CAPÍTULO 1; 1.1 Detalhando e amalgamando os fragmentos desse caleidoscópio de desastres; 1.2 Uma pincelada sobre as dimensões ética e epistemológica; CAPÍTULO 2; 2.1 Para além do apocalipse da pecuária: o veganismo como antídoto; 2.2 Frentes de luta contra o especismo e a destruição ambiental; conclusão; notas.

\section{INTRODUÇÃO}

Em 2006, a Organização das Nações Unidas para a Alimentação e a Agricultura (FAO) lançou um extenso relatório, o Livestock's Long Shadow ${ }^{1}$ - algo como "O grande rastro da pecuária" - o qual abordou de forma holística e minuciosa as diversas etapas de diferentes processos produtivos do referido setor. O relatório publicou dados alarmantes que atestam que a produção de carne e demais produtos de origem animal está diminuindo drasticamente a disponibilidade de recursos naturais renováveis e não renováveis, poluindo, danificando, ou consumindo tais recursos a um ritmo incompatível com sua taxa de renovação, além de prejudicar suas interações com vários ciclos biogeoquímicos dos quais depende a vida no planeta. A pecuária está causando e acelerando as mudanças climáticas tanto de forma direta, liberando gases de efeito estufa ao longo da cadeia de produção, quanto indiretamente, desencadeando o desmatamento e mudanças de grande monta no uso da terra. É também a grande responsável pelo empobrecimento, fragmentação e perda de habitats, fatores que lideram a atual queda vertiginosa de biodiversidade.

Outro estudo da FAO, de $2013^{2}$ - que enfoca a saúde global, humana e a segurança planetária na produção de alimentos - aponta que a maioria das novas doenças que surgiram nas últimas décadas são de origem animal e estão relacionadas à busca humana por mais alimentos de origem animal. Exemplos são as gripes aviária e suína, a encefalopatia espongiforme bovina, a SARS (Síndrome Respiratória Aguda Grave), o vírus Ebola e muitos outros riscos veterinários de saúde pública. Muito preocupante também é o uso de antibióticos - para prevenir doenças e estimular o crescimento de animais - e sua liberação não intencional no meio ambiente, através de esgotos e água de escoamento de áreas agrícolas ${ }^{3}$. Há evidências de que os antibióticos estão perdendo sua eficácia para a medicação humana por causa do uso rotineiro em fazendas industriais ${ }^{4}$. Esses esgotos são inclusive ricos em nitrogênio e fósforo, o que contribui para a formação de "zonas mortas" nos oceanos ${ }^{5}$ e para a degradação de recifes de coral, as "florestas tropicais" dos oceanos. A pecuária, que é também responsável pela disseminação massiva dos transgênicos e pelo uso indiscriminado de agrotóxicos, caracteriza-se ainda por sua forma termodinamicamente ineficiente de produzir alimentos: os sistemas agroalimentares industriais são enormemente dependentes do petróleo ${ }^{6}$. E o preço de tais produtos não reflete nenhum dos riscos ou danos mencionados. Esta reflexão - baseada em pesquisa de natureza bibliográfica e documental - visa a correlacionar de forma transdisciplinar as mais diversas facetas desta síndrome. O objetivo é desfraldar mais uma bandeira de luta contra essa avassaladora modalidade de ecocídio. 


\section{Capítulo 1}

1.1 Detalhando e amalgamando alguns fragmentos desse Caleidoscópio de DESASTRES

No Brasil, país onde há mais bovinos do que gente, temos uma área equivalente ao Cerrado apenas somando as pastagens e o cultivo de soja. Assim como o milho, a finalidade principal desses grãos é a sua transformação em ração animal. Tais grãos são em sua maior parte transgênicos - o que já causa danos7- e, no caso da soja, por exemplo, dependem de herbicidas perigosos, como o glifosato, que tem sido associado a diversos impactos negativos para animais, humanos e o meio ambiente8. O Brasil é responsável por $26 \%$ da área plantada com transgênicos no mundo9.

Segundo maior bioma da América do Sul, com mais de 200 milhões de hectares, é no Cerrado que se encontram as nascentes das três maiores bacias hidrográficas da América do Sul. Apenas $20 \%$ do bioma se encontra bem preservado, porque a maior parte é ocupada com pastagens e monoculturas de grãos que destroem sua rica biodiversidade, da base ao topo das cadeias tróficas10. Assim como na floresta amazônica, esse tipo de ocupação da terra debilita os mecanismos de evapotranspiração, a recarga de aquíferos, impacta a integridade de solos e, com isso, afeta o balanço hídrico do qual depende o regime de chuvas que abastece a própria agricultura e as cidades. Mesmo sem apontar outras funções importantíssimas das florestas, é fácil entender como essa única função - o balanço hídrico - impacta o clima em nível local, nacional e global: uma única árvore na floresta amazônica chega a colocar na atmosfera até 1.000 litros de água por dia11. Além disso, as árvores consomem uma enorme quantidade de dióxido de carbono, compensando os efeitos de queimadas e outras fontes de emissão de $\mathrm{CO} 2$ para a atmosfera, responsáveis pelas mudanças climáticas. Alterações nesse sistema têm repercussão nos dois hemisférios terrestres. No que tange às emissões de gases de efeito estufa, o cenário é sombrio: entre 1990 e 2013, o setor agropecuário teve alta de $46 \%$ no Brasil. Hoje este setor contribui com $55 \%$ das emissões, sendo $31 \%$ de forma direta e $24 \%$ resultante de mudanças do uso da terra (como o desmatamento ligado às pastagens e à agricultura)12. É preciso destacar ainda que, ao exportar grãos, exportamos a nossa água.

Em termos globais, um quarto da superfície terrestre é usada atualmente para pastagem de ruminantes e um terço da terra arável global é destinada ao cultivo de alimentos para o gado, representando $40 \%$ da produção total de cereais 13 . Mais de $80 \%$ do desflorestamento no Brasil, entre 1990 e 2005, foi causado pela conversão de terras em pastos. E em seis países analisados na América do Sul, a expansão de pastos causou a perda de ao menos um terço das florestas14. Como a destruição de habitats é a primeira causa de perda de biodiversidade, não é surpreendente que as populações de vertebrados (mamíferos, aves, répteis, anfíbios e peixes) tenham diminuído em abundância em 58\% entre 1970 e 2012, o que é uma "fração de segundo" geológico. Na América Latina, a queda é ainda mais dramática, da ordem de $83 \% 15$. Os números falam por si. No caso dos mamíferos terrestres, a pecuária exerce um impacto negativo gigantesco, pois a biomassa de espécies selvagens se reduziu a uma fração ínfima quando comparada à dos humanos, somada à dos animais explorados por este setor. Isso gera uma série de impactos negativos inclusive sobre os ciclos biogeoquímicos, afetando, por exemplo, o sequestro de carbono16. 
Com relação ao uso de água, a agricultura responde por $92 \%$ da pegada de água doce da humanidade, sendo que quase um terço diz respeito a produtos de origem animal17. Consequentemente, mesmo que o uso doméstico direto seja muito parcimonioso, o gasto maior está na água virtual, "invisível”, aquela necessária para se produzir tais produtos. Exemplos de alguns valores médios de pegadas hídricas globais por kg são: bovinos - 15.400 l; suínos - 5.900 l; e aves (galinha) - 4.300 118. Esses dados podem variar bastante, mas uma simples mudança para dietas vegetarianas/veganas reduziria a pegada hídrica relacionada à alimentação em 36\% ou mais19. Analisando os impactos para além das pegadas hídricas, é difícil afirmar qual espécie seria a mais impactante, uma vez que isso vai depender do tipo de dano analisado, da metodologia aplicada, e de particularidades de cada cadeia produtiva, como idade de abate, grau de confinamento, tipo de alimento (pasto ou grãos), etc. Mas mesmo no caso de alimentação a pasto - defendida por alguns setores como "exemplo de sustentabilidade" - existem outros gastos hídricos e energéticos substanciais, como no processamento das carcaças, por exemplo, e é preciso salientar que a água que cai sobre os pastos depende da evapotranspiração de florestas e outros biomas. Há ainda a imensa área ocupada por cada animal que, no caso de bovinos, é, em média, um animal por hectare. O confinamento reduziria muito esse último problema, mas criaria diversos outros, como um maior gasto de energia, por exemplo. No tocante à energia, vale citar um estudo que mostra que, se as terras destinadas a pastagens e à produção de ração fossem usadas para o plantio de culturas a serem convertidas diretamente em alimentos para os humanos e para a produção de biocombustíveis, tais combustíveis poderiam substituir cerca da metade do carvão utilizado em todo o mundo, evitando a emissão de 3.340 milhões de toneladas de CO2 anualmente20.

Devido ao fato de que muitos impactos negativos sobre o meio ambiente são o resultado do sinergismo de outros impactos, há uma infinidade de danos cuja detecção e quantificação são difíceis, pois dependem da existência de métodos confiáveis de mensuração, bem como do rigor metodológico relativo à sua correta aplicação. Também, em havendo iniciativas de práticas mitigatórias, o sucesso delas depende da eficácia do controle/monitoramento de tais expedientes. Exemplos desses contextos são a destinação das camas de aviário e dejetos da suinocultura, frequentemente descartados sem qualquer tratamento. Os referidos dejetos constituem fontes importantes de contaminação, além de causarem vários tipos de poluição, como a eutrofização acelerada de corpos d'água continentais e mesmo de áreas marinhas costeiras, como anteriormente citado.

Até aqui foi feita uma brevíssima síntese do panorama apocalíptico da pecuária unicamente sob a perspectiva ambiental tradicional, ou seja, dentro de uma ética conservacionista que desconsidera as dimensões social, ética, política e inclusive econômica, se considerarmos esta última no sentido lato de "oikosnomia", ou gestão da casa.

Muito ainda poderia ser dito acerca das externalidades negativas da pecuária, dentro dessa perspectiva essencialmente conservacionista e antropocêntrica. Um contexto antes mencionado é o da saúde humana. Há uma década e meia a Organização Mundial de Saúde já advertia que o aumento na produção e consumo de calorias de origem animal vem causando graves problemas para a saúde humana, sérios impactos ambientais e ainda dificultando o acesso dos mais pobres à comida. Em função disso, o relatório recomendava uma ação concertada entre diversos setores da sociedade e profundas mudanças nas políticas agrícolas21. Não é tampouco novo o conhecimento de que, à medida que um país 'subdesenvolvido' ingressa no estágio de 'desenvolvido', seus habitantes ascendem pela cadeia trófica 
e consomem cada vez mais carne22. De fato, o mesmo estudo da Organização Mundial de Saúde antes citado ratificou essa afirmação (p. 95), acrescentando que, à medida que os países em desenvolvimento se urbanizam, os padrões de câncer - incluindo aqueles associados às dietas alimentares - tendem a se igualar na direção do padrão dos países desenvolvidos. O relatório ressalta ainda que o câncer é hoje uma das maiores causas de mortes no mundo desenvolvido, superado apenas pelas doenças cardiovasculares. Recentemente tem surgido uma verdadeira avalanche de informações que atestam que a dieta ocidental dominante, baseada na exploração, sofrimento e morte dos animais, está mesmo afetando de forma muito adversa a saúde humana. Diabetes do tipo II, doenças cardiovasculares e obesidade, a qual, por sua vez, potencializa diversos tipos de câncer, estão direta ou indiretamente ligados a essa dieta especista23. Não poderia ser diferente. Somos parte da natureza. Tudo está interligado. A pecuária também se encontra frequentemente associada a formas de trabalho análogas à escravidão24, seja no campo, seja no trabalho em frigoríficos. Contudo, mesmo que assim não o fosse, lidar com cadáveres ou, pior, participar da chacina de seres sencientes é uma tarefa especista, abjeta, indigna de uma espécie que se autointitula "sapiens".

\subsection{UMA PINCELADA SObRe AS DIMENSÕes ética E EPISTEMOLÓGICA}

As questões elencadas até o presente momento da discussão já são suficientes para evidenciar a insustentabilidade da pecuária. Entretanto, é importante enfatizar que, ainda que fosse possível promover ações que a tornassem "sustentável", dentro da tradicional tríade "social - econômico - ambiental", no plano ético tal condição jamais poderia ser satisfeita. Ao polissêmico termo "desenvolvimento sustentável" vem sendo agregadas as mais diversas dimensões. Muitas delas, de fato, contribuem para tornar esse conceito mais completo. Porém, embora seu caráter polissêmico permita abrigar uma certa plasticidade, nenhuma dimensão além das três tradicionais pode ser mais importante do que a ética. $\mathrm{O}$ filósofo Herbert Marcuse destaca que a quantificação da natureza - sua tradução em estruturas matemáticas - separou a ciência da ética, projetando a natureza como mero substrato da teoria e da prática. Como tal pseudoneutralidade é o resultado de um processo (também) histórico, epistemologia e ética são inseparáveis25. O resgate de uma ciência por inteiro, assim como de uma sustentabilidade integral, passa, portanto, por esse prisma. No seio da dimensão ética, uma discussão evidente é a do apelo à nossa natureza animal no que tange à obtenção de alimentos. Todavia, em nossas sociedades industriais, não somos premidos pela necessidade de tirar a vida de outros animais, tal qual acontece no contexto dos povos caçadores-coletores. Em não se aplicando essa situação de necessidade, tudo o que fizermos nesse sentido é eticamente condenável. É especista.

Não é objetivo do presente artigo discorrer extensamente sobre o conceito de especismo, visto que tal debate se encontra fácil e fartamente disponível na literatura animalista atual. Suscintamente, essa palavra foi cunhada pelo psicólogo britânico Richard Ryder26, em 1970, para designar diversas formas de preconceitos praticadas pelos seres humanos contra outras espécies animais. O termo foi proposto em uma analogia ao racismo e ao sexismo, que também são formas de discriminação que se baseiam em diferenças moralmente irrelevantes. Ryder ressalta a capacidade de sofrer - ou seja, a senciência e a consciência acerca do sofrimento, físico ou não - como a única base convincente para atribuir direitos ou interesses a outros, sejam esses "outros" humanos ou não. Através da lente especista, dominante em nossa cultura, excluímos os animais não humanos da nossa comunidade moral e abrimos a guarda para que diversas formas de atrocidades sejam cometidas contra 
eles. E o contexto no qual tal massacre cotidiano ocorre em maior número é exatamente o da pecuária. Em suma, além dos riscos e externalidades negativas apontados antes, há o fato de essa indústria se caracterizar por práticas moralmente repugnantes.

Charles Darwin já havia descrito mais de vinte tipos diferentes de emoções nos animais. Algumas delas são: pesar, desespero, ternura, devoção, mau humor, amuo, determinação, ódio, culpa, desamparo, perplexidade e vergonha. Mas hoje sabemos - pela Declaração de Cambridge sobre Consciência27- que todos os mamíferos, aves e animais, como os polvos, possuem os substratos neurológicos associados aos estados conscientes e à capacidade de exibir comportamentos intencionais. Está comprovado que vários animais experimentam não apenas estados emocionais relativamente simples como a alegria, a angústia ou o medo, mas também são capazes de estabelecer regras complexas de convivência social e de exibir comportamentos relacionados ao luto, honra, empatia e justiça. Muitos mamíferos demonstram a capacidade de refletir sobre eventos futuros e, mesmo em animais considerados distantes de nós, como os peixes, há comprovação sobre sua capacidade de sentir dor e medo28. A questão não é mais, enfim, se os animais pensam, mas o que eles pensam29. É fundamental, por conseguinte, que entendamos que os animais são inteligentes (e pensam) na medida de suas necessidades. Estudos a respeito do comportamento e das emoções de "animais de criação" como galinhas, porcos, vacas, ovelhas e cabras também revelam a existência de emoções profundas e complexas como o amor, a lealdade, a amizade e a tristeza30.

Milhões desses seres são mortos todos os dias unicamente para satisfazer o paladar humano, já que não precisamos de nenhum produto de origem animal para promover nossa saúde31. Pior, é patético pensar que evidências recentes mostram que os carboidratos digestíveis e o cozimento de alimentos foram, estes sim, de suma importância para acomodar as crescentes demandas metabólicas de um cérebro em crescimento32. Em resumo, mesmo em escala evolutiva, o consumo de carne perdeu seu lugar de destaque como o principal fator para nosso florescimento como espécie e para o desenvolvimento do tão gabado cérebro humano. É inequívoco, portanto, que não mais se sustentam, ética ou cientificamente, os argumentos que tentam justificar o tratamento dos animais como meios, propriedades ou objetos para uso dos seres humanos33. É crucial assinalar ainda que o tratamento respeitoso dos animais é incompatível com a categoria de propriedade, mesmo que se alegue que tais seres podem ser "bem tratados". Cabe aqui fazer referência a um trecho do documentário The Corporation34, em que o linguista e filósofo Noam Chomsky afirma que embora um senhor de escravos possa ser gentil com o ser escravizado e tratá-lo bem, o problema é que a instituição - o escravagismo - é inerentemente monstruosa. O mesmo pode ser dito em relação à visão dos animais não humanos como propriedade.

Relações e regimes opressivos fazem parte de uma infinidade de momentos históricos de diversas culturas humanas. Contudo, é pertinente enfatizar aqui a solidez da ideia da hegemonia de uma racionalidade instrumental - e de uma ciência divorciada da ética como o fundamento teórico dessa relação de domínio e extorsão da natureza nas sociedades industriais em todas as suas formas, sejam elas sencientes ou não. Os animais não humanos explorados na pecuária, obviamente, estão sob o jugo dessa tirania. Desprovidos de qualquer valor intrínseco, para todos e todas há um prazo de vida pré-estabelecido antes mesmo de nascerem, um prazo de validade, uma "hora para morrer", como bem dito na fatídica frase do filme "Blade Runner"35: "Time to die". É interessante notar que, tanto no caso dos androides do filme, quanto dos animais reproduzidos para serem objetos de exploração humana, reivindica-se um direito absoluto sobre a vida e a morte desses seres sencientes, 
criados para a servidão. A execução sumária e massiva de pintainhos machos recém-nascidos na indústria de ovos, e o destino de bezerros machos na indústria de laticínios, são manifestações emblemáticas desse tratamento moralmente execrável que independe de questões como espécie ou sexo biológico. $\mathrm{O}$ fato de as fêmeas serem mais exploradas do que os machos acontece porque, devido à sua natureza biológica, elas têm mais "produtos" passíveis de apropriação espúria do que seus companheiros de espécie do sexo masculino. É muito provável que, se houvesse algum indício acerca da utilidade (real ou não) do sêmen de outros animais para uso humano direto, fosse adicionada mais uma engrenagem nesse mecanismo macabro: a ordenha, o roubo, dessa categoria de fluido animal.

Apesar do caráter cruel e do cenário multifacetado de insustentabilidade da pecuária, o Brasil e outros países no mundo insistem nessa trajetória extensivamente permeada por diversas categorias de riscos. No nosso caso, segundo o Banco Nacional de Desenvolvimento Econômico e Social (BNDES), “o Brasil é, e deve continuar a ser ao longo dos próximos anos, um dos principais fornecedores mundiais de produtos agropecuários. Na economia nacional, também é grande o peso das atividades agropecuárias: nos últimos dez anos, o agronegócio correspondeu a algo entre 22\% e 25\% do produto interno bruto (PIB) brasileiro36. Mas o que aconteceria com a ordem de grandeza de tal percentual de contribuição ao PIB, caso fossem removidos os vultosos subsídios que recebe esse setor37? E se, somado a isso, fossem quantificadas e monetizadas as suas externalidades negativas?

Lamentavelmente, o consumo de carne e de outros derivados de animais segue fazendo parte das dietas dominantes, embora a crescente população humana demande cada vez mais alimentos que poderiam ser providos por uma dieta baseada em plantas. É desconcertante pensar que a opção por esses produtos é considerada uma escolha de ordem estética, assim como outros hábitos de consumo pertencentes à esfera da vida privada. E é desanimador aquilatar que, em diversos contextos da vida moderna, não é a falta de conhecimento sobre os riscos de determinadas práticas o fator que atua como o fiel da balança no que toca a decisões que selam a continuidade ou não dessas práticas. Já existem casos em que o Estado tratou de viabilizar medidas e leis que coíbem ou punem hábitos considerados privados, quando estes são passíveis de causar danos a terceiros. Dirigir embriagado é um exemplo emblemático. Mas ainda precisamos avançar em muitos outros contextos.

Aqui vale lembrar, brevemente, algumas ideias do sociólogo Ulrich Beck38 sobre o que denominou por sociedade do risco. Os riscos - que se referem à insegurança e à incerteza que vivemos hoje, na chamada "segunda modernidade" - são basicamente as consequências do que plantamos na primeira modernidade, caracterizada por uma rápida industrialização e pela exploração "encafuada" da natureza. Tais riscos - que como diria Marcuse são inerentes a esse projeto histórico específico - são, além dos ecológicos, os financeiros, os informacionais, os sociais, os terroristas, etc. Giddens, Beck \& Lash39 enfatizam ainda que a tese proposta por Beck diz respeito a uma fase do desenvolvimento da sociedade moderna na qual os riscos escapam das instituições de controle. Isso acontece, em grande medida, porque apenas as evidências visíveis e quantificáveis seriam objeto de atenção, enquanto as relações de causa e efeito de natureza sistêmica, e portanto, de difícil mensuração, são negligenciadas.

No caso aqui analisado, não é a falta de lastro científico que impossibilita estabelecer nexos causais entre os problemas complexos citados. No entanto, as instituições e os setores sociais que auferem lucros advindos de tal setor ora optam por um silêncio cínico, ora pela atribuição a causas naturais de todo esse desastre de origem antrópica. 
É interessante notar que Beck já destacava que todas as sociedades selecionam os riscos aos quais vão dar atenção, enquanto muitos outros são simplesmente ignorados. Em outras palavras, há uma "irresponsabilidade organizada": embora haja uma consciência acerca da existência de riscos, cada vez mais pessoas, instituições e outros atores hegemônicos procuram concentrar os bônus provenientes de uma ciência que explora tudo o que é possível, ao mesmo tempo que externaliza toda sorte de danos para a sociedade em geral. No Brasil, e no mundo, quem está decidindo sobre os riscos é o mercado, com a conivência do Estado e o beneplácito de grande parte da sociedade civil.

\section{CApítulo 2}

\subsection{Para além do apocalipse da pecuária: o Veganismo como antídoto}

A greve de caminhoneiros que sacudiu o Brasil em maio de 2018 demonstrou de forma contundente a fragilidade de várias instituições e sistemas produtivos em nosso país. A pecuária foi um exemplo indiscutível. De acordo com a própria Associação Brasileira de Proteína Animal (ABPA), em Carta aberta ao Povo Brasileiro ${ }^{40}$, "no sétimo dia de paralisação a mortandade animal já era uma realidade devido à falta de condições minimamente aceitáveis de espaço e quantidade de ração. Um bilhão de aves e 20 milhões de suínos já estavam recebendo alimentação insuficiente. Com risco de canibalização e condições críticas para os animais, 64 milhões de aves adultas e pintinhos já haviam morrido, e um número maior seria sacrificado em cumprimento às recomendações da Organização Mundial de Saúde Animal e das normas sanitárias vigentes no Brasil. Milhões de suínos também estão ameaçados". Ainda nesta "Carta", a ABPA menciona que "os reflexos sociais, ambientais e econômicos são incalculáveis; e que uma intervenção rápida do Governo brasileiro seria urgente para evitar a continuidade da mortandade de milhões de animais, o desabastecimento dos brasileiros, problemas de saúde pública, danos ao meio ambiente e possível fechamento de agroindústrias e cooperativas, que empregam centenas de milhares de brasileiros e movimentam a economia nacional e o comércio internacional do país".

O sofrimento de tais seres indefesos não é uma preocupação dessa maquinaria da morte. Apesar de mencionarem que a ABPA "não tem poupado esforços para garantir o bem-estar animal", o teor do documento é iminentemente econômico e focado sobretudo nas "milhares de toneladas de alimentos ameaçadas de perderem prazo de validade, enquanto o consumidor já enfrenta a escassez de produtos (grifos nossos)". Apelam ainda para a questão do custo, para a possibilidade de "as carnes suína, de frango e os ovos, proteínas que antes eram abundantes e com preços acessíveis, se tornarem mais caras, caso a greve se estenda". A especista mídia mainstream ${ }^{41}$, além de ter tentado jogar a população contra os grevistas, se rendeu ao infeliz papel de publicar matérias e comentários hipócritas que lamentavam os episódios de morte de animais por inanição ou canibalismo durante a greve. Ora, a pecuária é o setor que mais pratica abusos e viola as leis ambientais e de bem-estar animal vigentes no Brasil e no mundo. Apesar de a legislação dominante ainda tratar os animais como propriedade, algo incompatível com a ciência do século XXI, tais leis procuram resguardá-los, minimamente, da crueldade extrema. Mesmo esse patamar moralmente raso é frequentemente descumprido por tal indústria. E tudo em nome do vil metal. 
Nesse mesmo período, veganos em todo o país - que não alimentam esse sistema porque não se alimentam de seus "produtos" - passaram muito bem com a sua dieta saborosa, multicolorida e rica em nutrientes. A maior parte dos alimentos que compôs seus pratos sequer necessitou de refrigeração. E não causou a exploração ou a morte de seres sencientes.

Foi citado antes que um quarto da superfície terrestre é destinada atualmente à pastagem de ruminantes e um terço da terra arável global ao cultivo de alimentos para o gado. Em escala nacional e global, a adoção de uma dieta vegana disponibilizaria imensas áreas de terra que poderiam ser plantadas com uma enorme diversidade de vegetais que seriam comidos diretamente pelos seres humanos. Há ainda a questão da vida selvagem. A liberação dos espaços reservados à produção animal faria uma enorme diferença, tornando possível a recuperação de territórios antes ocupados pela nossa fauna selvagem. Os predadores de topo, por exemplo, indispensáveis à boa saúde dos ecossistemas, se beneficiariam sobremaneira, uma vez que necessitam de extensas áreas para encontrar suas presas relativamente dispersas.

Vale sublinhar, ainda, que há duas tendências principais de domesticação de plantas: o grain model, que trata do cultivo de cereais através da 'agricultura', e o garden model, destinado a múltiplos propósitos através da 'horticultura'. O grain model - aplicado em larga escala - além de ser histórica e ecologicamente incompatível com a diversidade dos trópicos, só oferece vantagens para os grandes empresários e exportadores que lucram com a produção de alimentos para animais. Os gardens, por outro lado, foram e ainda são o maior componente da agricultura indígena nos trópicos ${ }^{42}$. Todavia, embora os modelos de horticultura sejam mantenedores eficientes da complexidade dos ecossistemas naturais, foram preteridos em função de um processo de imperialismo histórico em favor do cultivo de grãos, tido como mais "eficiente". Essas duas tendências se materializam na dicotomia commodities $x$ agricultura familiar.

Já existem movimentos no sentido de recuperar a diversidade de alimentos vegetais que perdemos durante a primeira modernidade. Diversos restaurantes veganos, por exemplo, vêm oferecendo em seus cardápios cada vez mais opções de plantas alimentícias não convencionais (PANC). Além do aspecto estritamente ecológico, de que tais plantas podem florescer nos espaços antes destinados à agricultura animal, contribuindo para a biodiversidade, esses alimentos - "desenhados pela mãe-natureza" - abrigam uma enorme gama de nutrientes em quantidades seguras para nossa saúde, ao contrário de muitos suplementos cujos benefícios são controversos ${ }^{43}$.

A adoção de dietas veganas pode dar também um impulso gigantesco ao movimento mundial de hortas urbanas ${ }^{44}$ e redesenhar as nossas cidades. A esmagadora maioria dos ambientes urbanos caracteriza-se por um verdadeiro "vampirismo energético", pois consomem energia e recursos naturais provenientes de outros ecossistemas, sejam eles naturais ou gerenciados pelos humanos, como os agroecossistemas. É bastante inadequado, por conseguinte, o termo "ecossistema urbano". Entretanto, se nossa alimentação se movesse em direção à base da pirâmide trófica, teríamos muito mais energia à disposição e menos dependência de outros ecossistemas. Isso aliviaria sobremaneira a nossa pegada ecológica, além de ser um passo na direção de sistemas autogestionários e resilientes. Muitos desdobramentos positivos surgiriam em cadeia, a partir da adoção desse único expediente, como a geração de empregos, a melhoria do ar das cidades e a economia de energia para transporte de alimentos, para citar apenas alguns. 
Da viabilidade e dos benefícios da dieta vegana às evidências científicas acerca da senciência e consciência nos animais, a adesão ao veganismo - movimento social que visa ao fim de todas as formas de exploração dos animais - seria muito mais eficiente do que programas como o "Bolsa Verde", ou os controversos "pagamentos por serviços ambientais" 45. Os dois últimos, baseados em fundamentos econômicos, além de estarem sujeitos a diferentes pressões políticas, dependem de quantificações e monetizações que dificilmente refletem os reais danos em questão ${ }^{46}$. Já o veganismo baseia-se numa postura ética. Essa vanguarda abolicionista do século XXI está em franca ascensão em diversas partes do mundo, e no Brasil não é diferente: está presente na educação, na moda, na gastronomia, nas redes sociais e em diversos domínios culturais e vivências do nosso cotidiano ${ }^{47}$.

Porém, tanto no Brasil quanto no resto do mundo, o movimento floresce mais nos espaços privados. Embora os impactos negativos da pecuária estejam amplamente documentados, políticas públicas, por exemplo, são ainda muito escassas, tímidas ou inexistentes. Na esfera pública, um exemplo louvável foi dado pela ministra do Meio Ambiente da Alemanha, Barbara Hendricks, que anunciou que seu ministério não serviria mais carne, peixe ou derivados de carne em funções oficiais. Ela argumenta que seu ministério deve ser um modelo em questões ambientais e de sustentabilidade ${ }^{48}$. No Brasil, país onde a bancada ruralista é muito forte ${ }^{49}$, a implementação de iniciativas assim encontrariam uma miríade de obstáculos. É preciso, urgentemente, que a população entenda a interconexão das mais diversas formas de opressão para que os poucos políticos e membros da sociedade em geral que lutam contra elas não esmoreçam em batalhas inglórias. Existe hoje um retrocesso socioambiental e ético que há muito não se via: é projeto de lei para a legalização da caça (PL6268); é exportação de gado vivo em "navios da morte"; é emenda à constituição para maquiar de "cultura" a crueldade inerente às vaquejadas (EC 96) $)^{50}$, e a lista continua. Há ainda os ataques aos povos indígenas e quilombolas e o consequente aumento da violência no campo, perda de biodiversidade linguística, etc ${ }^{51}$. Todas essas abominações se encontram inextricavelmente ligadas à forma dominante de produzir "comida" (na verdade, commodities) em nosso país. Em termos de justiça intergeracional, fica a pergunta: que legado estamos deixando para as crianças e os jovens de hoje? E para os que nem nasceram?

\subsection{Frentes de luta contra o especismo e a destruição ambiental}

O Brasil tem uma legislação razoavelmente avançada no que concerne ao meio ambiente e mesmo no que diz respeito aos animais. No entanto, existe uma lacuna substancial entre a teoria e a prática, geralmente decorrente de conflitos de interesses relativos a questões econômicas. Essa inconsistência também está presente, é claro, em outros países onde leis análogas existem. Mas outro problema em defender o meio ambiente e os animais apenas por meio da legislação é o fato de que novas leis podem rebaixar as pré-existentes, mais restritivas. Embora nossa Constituição abrigue um princípio de não retrocesso, diversas novas leis e emendas desafiam tal norma, causando imensos danos sociais, éticos e ambientais. Este é tipicamente o caso de muitos projetos de lei e emendas profundamente impregnados pelos interesses do setor agropecuário, como os citados antes. Uma legislação robusta é absolutamente necessária, assim como políticas públicas derivadas de tais leis ou princípios éticos. Todavia, não haverá uma mudança palpável apenas via práticas coercitivas, confinadas ao universo legal, ou a políticas públicas. 
Para promover uma genuína mudança de paradigma, precisamos de uma educação que exponha as conexões entre os pilares de nossa cultura ocidental - dominada por uma visão de mundo mecanicista e por uma racionalidade instrumental - e a atual crise ética, ambiental, social, econômica e política. Para além da exploração máxima da natureza tout court, é essa racionalidade que faz com que seres humanos em condições de vulnerabilidade e animais não humanos sejam submetidos a horríveis condições de trabalho, de vida e de morte, em nome da eficiência e produtividade. Para os animais a situação pode ficar muito sombria porque, conforme a legislação vigente, eles não são portadores de valor intrínseco. A inclusão de uma dimensão abolicionista animal na educação formal e na legislação andaria, portanto, de mãos dadas com a inclusão da ética como uma dimensão da sustentabilidade.

No domínio educacional, isso acontece porque a educação tradicional, "não ambiental", legitima valores que são avessos a uma ética que poderia ser descrita como correta no que tange à relação entre nós e as outras espécies animais. E mesmo muitas correntes educacionais que se autointitulam como "ambientais" são guiadas por uma ética conservacionista rasa que tolera a exploração animal e trivializa práticas especistas, como o abate de espécies consideradas "nocivas" às atividades humanas ${ }^{52}$. O famigerado "PL da caça", citado antes, encontra nesse reduto moralmente vazio um salvo conduto para prosperar. É triste pensar que o paradigma dominante na educação seja incapaz de acolher as evidências científicas acerca da senciência animal. Disso decorre a impossibilidade de uma formação em que haja compaixão ou mesmo respeito pelos animais rotulados como pragas, além daqueles reproduzidos em laboratórios, etc. Essa visão, porém, está em conflito com a manutenção da própria biodiversidade, pois a evolução da senciência foi um ponto de mutação crucial que afetou todos os animais na história biológica ${ }^{53}$. A pujança da biodiversidade depende, em muitos casos, muito mais da nossa não ação do que de controversas intervenções antrópicas, como repovoamentos com animais "sem-terra", criados em cativeiros. A realidade é que falta território para a vida selvagem. Mas isso pode ser resolvido a curto prazo, disponibilizando as áreas no planeta que hoje ocupamos para satisfazer o desejo hedonista de "comer animais".

As atuais formas de proteção dos animais - legislação, políticas públicas, educação enraizadas na categoria impessoal de "fauna", têm se mostrado insuficientes. A educação ambiental dominante deixou um saldo devedor ao perpetuar o especismo e os falsos dilemas como "desenvolvimento" versus conservação, seja de forma explícita, seja via "currículo oculto" 54 . Os animais não são vistos como sujeitos de suas vidas, mas como objetos de aprendizagem, pesquisa ou meros guardiões das funções ecológicas. Discussões envolvendo as causas da extinção de espécies, ou mudança climática - todas relacionadas ao especismo - também estão ausentes nesses universos cruciais de mudança.

Para que a educação seja um vetor efetivo de transformação, é preciso haver uma "anastomose" entre o ambientalismo e os direitos animais. Embora haja convergências entre as éticas ambiental e animal, é fácil testemunhar debates acirrados envolvendo ambientalistas e defensores dos direitos dos animais. Ambos os campos concordam que o antropocentrismo está no cerne de todos os males que afetam o meio ambiente e os animais não humanos. Entretanto, não há consenso sobre o que sejam práticas antropocêntricas. A ética ambiental nasceu e se consolidou em um contexto histórico no qual os estudos sobre senciência animal eram anedóticos e incipientes. Mas, como vimos, esse não é mais o caso. Por conseguinte, não é mais razoável acusar os defensores dos direitos dos animais de diminuir 
a importância das espécies e ecossistemas, levando em conta apenas o bem-estar de indivíduos, como frequentemente ocorre. Na verdade, a perspectiva dos direitos animais transcende a racionalidade do conservacionismo estrito ao adicionar um elemento ético que vai além da mera manutenção da biodiversidade como um "serviço ambiental".

Analogamente, as legislações brasileira e mundial deveriam andar pari passu com os mais recentes resultados da ciência. Vamos a um exemplo elementar, tomando unicamente o que está sacramentado na Declaração de Cambridge sobre Consciência: se todos os mamíferos, aves e animais, como os polvos, possuem os substratos neurológicos associados aos estados conscientes, pelos menos esses animais teriam que ser titulares de alguns direitos mínimos, análogos aos humanos, como o de não ser tratado como propriedade, não ser aprisionado e não ser morto, por exemplo. Isso seria fazer justiça, tanto no sentido lato quanto estritamente técnico, visto que estaríamos exercitando a coerência ao honrar os desdobramentos éticos daquele estudo científico. Considerando que a grande maioria dos animais explorados e chacinados na pecuária são sobretudo os mamíferos e as aves, isso seria o início do fim dessa indústria cuja insustentabilidade é ubíqua, além de ser cruel e desnecessária. Esta seria tão somente uma etapa na longa caminhada por justiça para além da espécie humana. Mas seria uma etapa e tanto!

\section{CONCLUSÃo}

Na era atual, o "Antropoceno" 55 , uma preocupação genuína com o futuro dos animais não humanos e do planeta, envolve o questionamento de nossa estreita visão de mundo dominada por uma racionalidade instrumental.

A educação formal e o universo legal são as vias mais privilegiadas de mudança em direção a um novo paradigma sistêmico, não especista. Mas tais fontes de transformação não podem permanecer em seu confortável anacronismo. É certo que, se nem sob a égide rasa da categoria de fauna os animais não humanos vêm recebendo a devida proteção e respeito que lhes são devidos, ainda mais difícil é, em tese, a garantia de sua integridade física e psicológica, como sujeitos de direito. Mas esse é precisamente o desafio inadiável da educação formal em todas as áreas, sendo a área do Direito um contexto de suma relevância. É mister aquilatar que, enquanto o ensino formal perpetuar o paradigma especista, dificilmente as leis mudarão: cada cidadão (de)formado por essa visão de mundo estreita e fragmentada tratará de reproduzir e legitimar o estatuto legal dos animais como propriedades. Importante frisar, outrossim, que não bastará uma anastomose entre o ambientalismo e os direitos animais, mas também entre esta última e todas as outras áreas do conhecimento: desde a economia e a engenharia de produção, que tratam os animais como "estatísticas"; passando pelo ensino das ciências da "vida" que banalizam a tortura e a morte de animais em laboratórios, ou aos cursos de nutrição que reproduzem informações errôneas sobre os produtos de origem animal; até as áreas de ciências humanas que legitimam barbáries como a farra do boi, naturalizando tais práticas como um direito à diversidade cultural.

Existe também uma relação dialética entre o domínio educacional e o legal. Embora o primeiro seja mais afeito à liberdade com consciência da necessidade, enquanto o segundo seja mais ligado a práticas mandatórias, no mundo vivido não existe tal dicotomia: há coerção nas práticas educativas e as leis também educam. Por essa razão, tal parceria tem tudo para promover um salto qualitativo de imensurável alcance. 
Em seu livro Our Final Hour, o astrofísico britânico Martin Rees ${ }^{56}$ destaca que o tempo em que vivemos está repleto de ameaças e riscos de grande magnitude e que a humanidade tem $50 \%$ de chance de se extinguir ainda neste século. Nesse sentido, uma das missões mais importantes da nossa época é vencer o especismo.

Assim como para o economista ecológico Herman Daly o "crescimento sustentável" da economia é um oximoro ${ }^{57}$, o mesmo pode ser dito com relação à pecuária. Como discutido antes, ela só poderia ser parcialmente sustentável eliminando a dimensão ética, com vistas a chancelar a chacina de seres sencientes unicamente para atender as exigências do paladar humano. Mas este é um motivo torpe, que exige uma mudança no posicionamento do observador humano a fim de perpetuar a ilusão de que os animais não passam de coisas. Considerando as evidências que temos hoje, seria essa então uma espécie de paralaxe?

É preciso que haja o ocaso da pecuária - o seu "apocalipse", para que este setor não seja, ele sim, um "cavaleiro do apocalipse". Abraçar os direitos dos animais não vai resolver tudo. E o veganismo não é a resposta para todos os problemas complexos do mundo atual: há uma infinidade de outros candidatos a "cavaleiros do apocalipse", como a indústria nuclear e os setores petroquímico e farmacêutico. Mas a adoção dessa pauta de conduta ética pode evitar que deixemos pegadas indeléveis na história do planeta. E a excelente notícia é que se trata do setor sobre o qual mais facilmente podemos agir aqui e agora. Basta não permitir que a crueldade com os animais sente-se à mesa conosco.

Que esse novo mundo floresça já. Mas, para tanto, os universos educacional e legal têm que viver consoantes com a novas verdades que emergem dos domínios ético e científico.

\section{Notas}

1. STEINFELD, H.; GERBER, P.; WASSENAAR, T.; et al. Livestock's Long Shadow: environmental issues and options. Rome, Italy: Food and Agriculture Organization (FAO), 2006. Disponível em: <http://www.fao.org/docrep/010/a0701e/a0701e.pdf>. Acesso em: 28 jun. 2018.

2. FOOD AND AGRICULTURE ORGANIZATION (FAO). World Livestock 2013: Changing disease landscapes. Rome, Italy, 2013. Disponível em: <http://www.fao.org/docrep/019/i3440e/i3440e. pdf>. Acesso em: 28 jun. 2018.

3. INFOGRAPHICS: antimicrobial resistance in the food chain. World Health Organization (WHO), nov. 2017. Disponível em: <http://www.who.int/foodsafety/areas_work/antimicrobial-resistance/AMR-food-chain-infographics/en/>. Acesso em: 07 jul. 2018.

4. FOOD AND WATER WATCH (FWW). Antibiotic Resistance 101: How antibiotic misuse in factory farms can make you sick. Washington, DC/Oakland/CA, USA: FWW, 2015. Disponível em: <https://www.foodandwaterwatch.org/sites/default/files/Antibiotic\%20Resistance $\% 20101 \% 20$ Report\%20March\%202015.pdf>. Acesso em: 07 jul. 2018.

5. SHAUBER, G. Cows, Pigs and Poultry - The leading cause of ocean dead zones? UBC Blogs, $07 \mathrm{fev}$. 2017. Disponível em: <https://blogs.ubc.ca/makingwaves/2017/02/07/cows-pigs-and-poultry-the-leading-cause-of-ocean-dead-zones/>. Acesso em: 28 jun. 2018.

6. CAROLINE. Uma alimentação dependente do petróleo. Instituto Humanitas Unisinos, 06 maio 2014. Disponível em: <http://www.ihu.unisinos.br/78-noticias/530994-uma-alimentacao-dependente-do-petroleo>. Acesso em: 28 jun. 2018. 
7. CAMPOS, R. Influência do cultivo de milho transgênico em organismos não-alvo (Coleoptera: Scarabaeinae) e da ingestão indireta através da cadeia trófica. 2016. 140 f. Tese (Doutorado em Ecologia) - Programa de Pós-Graduação em Ecologia, Universidade Federal de Santa Catarina, Florianópolis, 2016.

8. WORLD HEALTH ORGANIZATION (WHO). International Agency for Research on Cancer (IARC). Monographs in the Evaluation of Carcinogenic Risks to Humans - Some Organophosphate Insecticides and Herbicides. Vol. 112. Geneva 27, Switzerland, 2017. Disponível em: <http:/ / monographs.iarc.fr/ENG/Monographs/vol112/mono112.pdf>. Acesso em: 27 jun. 2018; BAIN, C.; SELFA, T.; DANDACHI, T.; et al. 'Superweeds' or 'survivors'? Framing the problem of glyphosate resistant weeds and genetically engineered crops. In: Journal of Rural Studies, apr. 2017. Disponível em: <https://www.researchgate.net/publication/315067298_\%27Superweeds\%27_ or_\%27survivors\%27_Framing_the_problem_of_glyphosate_resistant_weeds_and_genetically_engineered_crops>. Acesso em: 27 jun. 2018; BALBUENA, M. S.; TISON, L.; HAHN, M. L.; et al. Effects of sublethal doses of glyphosate on honeybee navigation. In: Journal of Experimental Biology, 218: 2799-2805, 2015. Disponível em: <http://jeb.biologists.org/content/218/17/2799>. Acesso em: 27 jun. 2018.

9. BRASIL é responsável por $26 \%$ da área plantada com transgênicos no mundo, aponta estudo inédito. Conselho de Informações sobre Biotecnologia (CIB), 26 jun. 2018. Disponível em: <https:/ / cib. org.br/isaaa-2018/>. Acesso em: 26 jun. 2018.

10. COSTA, C. Em 30 anos, Cerrado brasileiro pode ter maior extinção de plantas da história, diz estudo. BBC Brasil, São Paulo, 23 mar. 2017. Disponível em: <http://www.bbc.com/portuguese/ brasil-39358966>. Acesso em: 25 jun. 2018.

11. O QUE são os 'rios voadores' que distribuem a água da Amazônia. BBC Brasil, São Paulo, 01 set. 2017. Disponível em: <http://www.bbc.com/portuguese/brasil-41118902>. Acesso em: 25 jun. 2018.

12. MINISTÉRIO DA CIÊNCIA, TECNOLOGIA, INOVAÇÕES E COMUNICAÇÕES (MCTIC). Estimativas anuais de emissões de gases de efeito estufa no Brasil. Disponível em: <http://sirene.mcti. gov.br/documents/1686653/1706227/4ed_ESTIMATIVAS_ANUAIS_WEB.pdf/a4376a93-c80e-4d9f-9ad2-1033649f9f93>. Acesso em: 25 jun. 2018

13. GERBER, P. J.; STEINFIELD, H.; HENDERSON, B.; et al. Tackling climate change through livestock: a global assessment of emissions and mitigation opportunities. Rome, Italy: Food and Agriculture Organization (FAO), 2013. Disponível em: <http://www.fao.org/docrep/018/i3437e/ i3437e.pdf>. Acesso em: 25 jun. 2018.

14. FAO: pastoreio causou $80 \%$ do desflorestamento no Brasil entre 1990-2005. Nações Unidas do Brasil (ONUBR), 18 jul. 2016. Disponível em: <https:/ / nacoesunidas.org/fao-pastoreio-causou-80-do-desflorestamento-no-brasil-entre-1990-2005/>. Acesso em: 25 jun. 2018.

15. WORLD WIDE FUND FOR NATURE (WWF). Living planet report 2014: Summary. Gland, Switzerland: WWF, 2014. Disponível em: <http://assets.wwf.org.uk/downloads/living_planet_report_2014_summary.pdf?_ga=1.38233059.1148581730.1413300010>. Acesso em: 25 jun. 2018; WORLD WIDE FUND FOR NATURE (WWF). Living planet report 2016: Summary. Gland, Switzerland: WWF, 2016. Disponível em: <http:/ / awsassets.panda.org/downloads/lpr_living_planet_ report_2016_summary.pdf>. Acesso em: 25 jun. 2018.

16. SMITH, F. A.; DOUGHTY, C. E.; MALHI, Y.; et al. Megafauna in the Earth system. In: Ecography, 39(2), 99-108, 2016.

17. GERBENS-LEENES, P. W.; MEKONNEN, M. M.; HOEKSTRA, A. Y. The waterfootprint of poultry, pork and beef: A comparative study in different countries and production systems. In: Water Resources and Industry, 1-2 (2013)25-36, 2013. Disponível em: <http://dx.doi.org/10.1016/j. 
wri.2013.03.001>. Acesso em: 25 jun. 2018.

18. WATER FOOTPRINT OF CROP AND ANIMAL PRODUCTS: a comparison. Water Footprint Network. Disponível em: <http://waterfootprint.org/en/water-footprint/product-water-footprint/ water-footprint-crop-and-animal-products/>. Acesso em: 25 jun. 2018.

19. GERBENS-LEENES, P. W.; MEKONNEN, M. M.; HOEKSTRA, A. Y. The waterfootprint of poultry, pork and beef: A comparative study in different countries and production systems. In: Water Resources and Industry, 1-2 (2013)25-36, 2013. Disponível em: <http://dx.doi.org/10.1016/j. wri.2013.03.001>. Acesso em: 25 jun. 2018.

20. GOODLAND, R.; ANHANG, J. Livestock and climate change: What if the key actors in climate change are... cows, pigs and chickens? In: World Watch Magazine, 22(6), 10-19, 2009. Disponível em: <http://www.worldwatch.org/files/pdf/Livestock\%20and\%20Climate\%20Change.pdf>. Acesso em: 23 jun. 2018.

21. WORLD HEALTH ORGANIZATION (WHO). Diet, nutrition and the prevention of chronic diseases. Technical Report Series n. 916. Geneva, Switzerland, pp. 140-141, 2003. Disponível em: <http://apps.who.int/iris/bitstream/handle/10665/42665/WHO_TRS_916.pdf;jsessionid=AD5600561A650739A892F963860E0BE7?sequence=1>. Acesso em: 07 jul. 2018.

22. RIECHMANN, J. Menos carne, mejor carne, vida para el campo - reflexiones sobre ecologia, ética y dieta. In: El Ecologista, (17), 1999: 30-34.

23. SUSMAN, C. Dr. Neal Barnard touts vegan diet for diabetes, heart disease, in MorseLife talk. Disponível em: https://www.palmbeachdailynews.com/lifestyles/health/neal-barnard-touts-vegan-diet-for-diabetes-heart-disease-morselife-talk/oyPaeJBptVupnW3C3F5FkO/>. Acesso em: 25 jun. 2018.

24. MOTOKI, C.; BROGGI, F.; FALCÃO, S. N.; et al. Moendo gente: a situação do trabalho nos frigoríficos. São Paulo, Brasil: Repórter Brasil, 2013. Disponível em: <http://reporterbrasil.org.br/wp-content/uploads/2015/02/16.-moendo_gente_final.pdf>. Acesso em: 21 jun. 2018; DE OLHO NOS RURALISTAS. Pecuária, café e madeira lideraram casos de trabalho escravo em 2016. Justificando, 19 jan. 2017. Disponível em: <http://justificando.cartacapital.com.br/2017/01/19/pecuaria-cafe-e-madeira-lideraram-casos-de-trabalho-escravo-em-2016/>. Acesso em: 22 jun. 2018.

25. MARCUSE, H. A ideologia da sociedade industrial - o homem unidimensional. $6^{\mathrm{a}}$ ed. Trad. Giasone Rebuá. Rio de Janeiro: Zahar, 1982.

26. RYDER, R. All beings that feel pain deserve human rights - Equality of the species is the logical conclusion of post-Darwin morality. The Guardian, 06 ago. 2005. Disponível em: <https://www. theguardian.com/uk/2005/aug/06/animalwelfare>. Acesso em: 25 jun. 2018.

27. THE Cambridge declaration on consciousness. Your Brain and You, 22 ago. 2012. Disponível em: <http:/ / yourbrainandyou.com/2012/08/24/the-cambridge-declaration-on-consciousness/>. Acesso em: 25 jun. 2018.

28. BEKOFF, M. The emotional lives of animals: a leading scientist explores animal joy, sorrow and empathy - and why they matter. Novato, CA: New World Library, 2007.

29. BALCOMBE, J. Second Nature - The inner lives of animals. New York: Palgrave Macmillan, 2010.

30. MASSON, J. M. O porquinho que cantava à lua - o mundo das emoções dos animais domésticos. Coleção Outro Olhar. Lisboa: Sinais de Fogo, 2005.

31. CRAIG, W.; MANGLES, A. Position of the American Dietetic Association: Vegetarian diets. In: Journal of the American Dietetic Association, 109(7), 1266-1282, 2009.

32. HARDY, K.; BRAND-MILLER, J.; BROWN, K. D.; THOMAS, M. G.; COPELAND, L. The Importance 
of Dietary Carbohydrate in Human Evolution. In: The Quarterly Review of Biology, 90(3):251-268, 2015. Disponível em: <https://www.jstor.org/stable/10.1086/682587?seq=1\#page_scan_tab_contents>. Acesso em: 25 jun. 2018.

33. FRANCIONE, G. Animals: Property or persons? In: SUNSTEIN, C.; NUSSBAUM, M. (Eds). Animal rights: Current debates and new directions. New York, NY: Oxford University Press, 2004; REGAN, T. Empty cages: Facing the challenge of animal rights. Lanham, MD: Rowman \& Littlefield Publishers, 2004.

34. THE Corporation. Direção: Mark Achbar e Jennifer Abbott. Produção: Mark Achbar. Intérpretes: Chris Barrett, Jane Akre, Maude Barlow, Michael Moore, Milton Freidman, Naomi Klein, Noam Chomsky, Peter Drucker, Ray Anderson, Samuel Epstein. Toronto International Film Festival, Canadá, 2003. 2 DVDs (144 min), widescreen anamórfico, color.

35. BLADE Runner. Direção: Ridley Scott. Produção: Michael Deeley. Intérpretes: Harrison Ford; Rutger Hauer; Sean Young; Edward James Olmos e outros. Roteiro: Hampton Fancher e David Peoples. Música: Vangelis. Los Angeles: Warner Brothers, c1991. 1 DVD (117 min), widescreen, color.

36. AGROPECUÁRIA sustentável e crédito rural no Brasil. Banco Nacional do Desenvolvimento (BNDES), Brasília, 31 mar. 2017. Disponível em: <https://www.bndes.gov.br/wps/portal/site/home/ conhecimento/noticias/noticia/credito-rural>. Acesso em: 22 jun. 2018.

37. MOTOKI, C.; BROGGI, F.; FALCÃO; et al. Moendo gente: a situação do trabalho nos frigoríficos. São Paulo, Brasil: Repórter Brasil, 2013. Disponível em: <http://reporterbrasil.org.br/wp-content/ uploads/2015/02/16.-moendo_gente_final.pdf>. Acesso em: 21 jun. 2018.

38. BECK, U. La sociedad del riesgo. Barcelona: Paidós, 1997.

39. GIDDENS, A.; BECK, U.; LASH, S. Modernização reflexiva. Política, tradição e estética na ordem social moderna. São Paulo: UNESP, 1997.

40. CARTA aberta ao povo brasileiro. Associação Brasileira de Proteína Animal (ABPA), São Paulo, 27 maio 2018. Disponível em: <http://abpa-br.com.br/noticia/carta-aberta-ao-povo-brasileiro-2452>. Acesso em: 24 jun. 2018.

41. BRÜGGER, P. It's the speciesism, stupid! Animal Abolitionism, Environmentalism and the Mass Media. In: BOGUEVA DIANA, D.; MARINOVA, D.; RAPHAELY, T. Handbook of Research on Social Marketing and Its Influence on Animal Origin Food Product Consumption. IGI Global, Hershey, pp. 92-103, 2018.

42. MICHON, G.; FORESTA, H. Agroforests: pre-domestication of forest trees or true domestication of forest ecosystems? In: Netherlands Journal of Agricultural Science 45, 451-462, 1997; BRÜGGER, P. Amigo animal - reflexões interdisciplinares sobre educação e meio ambiente: animais, ética, dieta, saúde, paradigmas. Florianópolis: Letras Contemporâneas, 2004.

43. BRÜGGER, P. Amigo animal - reflexões interdisciplinares sobre educação e meio ambiente: animais, ética, dieta, saúde, paradigmas. Florianópolis: Letras Contemporâneas, 2004.

44. HALL, M. Turning gray into green: Urban farming around the world. DW made for minds, 11 set. 2017. Disponível em: <http://www.dw.com/en/turning-gray-into-green-urban-farming-aroundthe-world/g-40423158>. Acesso em: 22 jun. 2018.

45. SILVERTOWN, J. Have ecosystem services been oversold? In: Trends in Ecology \& Evolution, 30(11), 641-648, 2015.

46. MARTINEZ ALIER, J. De la economia ecológica al ecologismo popular. $2^{a}$ ed. Barcelona: Icaria, 1994.

47. CRUZ, L. Veganismo cresce exponencialmente em 2017. Agência de Notícias de Direitos Animais 
(ANDA), 31 dez. 2017. Disponível em: <https://www.anda.jor.br/2017/12/veganismo-cresce-exponencialmente-em-2017/>. Acesso em: 25 jun. 2018.

48. MOSBERGEN, D. German environment minister bans meat at official functions. Huffpost, 22 set. 2017. Disponível em: <https:/ / www.huffingtonpost.com/entry/germany-meat-ban-environment-ministry_us_58ae1b24e4b01406012f962b>. Acesso em: 25 jun. 2018.

49. BRÜGGER, P.; MARINOVA, D.; RAPHAELY, T. Animal production and consumption: An ethical educational approach. In: RAPHAELY, T.; MARINOVA, D. (Eds). Impact of meat consumption on health and environmental sustainability, pp. 295-312. Hershey, PA: IGI Global, 2016.

50. RISCO AMBIENTAL - Projeto de Lei pode liberar caça aos animais silvestres do Brasil. Jusbrasil, 07 mar. 2017. Disponível em: <https://lfg.jusbrasil.com.br/noticias/436552163/risco-ambiental-projeto-de-lei-pode-liberar-caca-aos-animais-silvestres-do-brasil>. Acesso em: 24 jun. 2018; VIEIRA, S. Promulgada Emenda Constitucional que libera prática da Vaquejada. Senado Notícias, Brasília, 06 jun. 2017. Disponível em: <http://www12.senado.leg.br/noticias/materias/2017/06/06/promulgada-emenda-constitucional-que-libera-pratica-da-vaquejada>. Acesso em: 24 jun. 2018.

51. ANTUNES, A. A escalada da violência no campo: 2016 foi o mais violento dos últimos 13 anos. EcoDebate, 27 jan. 2017. Disponível em: <https://www.ecodebate.com.br/2017/01/27/escalada-da-violencia-no-campo-2016-foi-o-mais-violento-dos-ultimos-13-anos/>. Acesso em: 21 jun. 2018; LÍNGUAS. Povos Indígenas no Brasil. Instituto Socioambiental (ISA). Disponível em: <https:/ / pib.socioambiental.org/pt/c/no-brasil-atual/linguas/introducao>. Acesso em: 21 jun. 2018.

52. BRÜGGER, P.; MARINOVA, D.; RAPHAELY, T. Animal production and consumption: An ethical educational approach. In: RAPHAELY, T.; MARINOVA, D. (Eds). Impact of meat consumption on health and environmental sustainability, pp. 295-312. Hershey, PA: IGI Global, 2016.

53. BEKOFF, M. The emotional lives of animals: a leading scientist explores animal joy, sorrow and empathy - and why they matter. Novato, CA: New World Library, 2007; BALCOMBE, J. Second Nature - The inner lives of animals. New York: Palgrave Macmillan, 2010.

54. BRÜGGER, P. Educação ou adestramento ambiental? $3^{\mathrm{a}}$ ed. Chapecó: Argos/ Florianópolis: Letras Contemporâneas, 2004.

55. LEWIS, S.; MASLIN, M. Defining the Anthropocene. In: Nature, 519 (7542), 171-180, 2015.

56. REES, M. Our final Hour: A Scientist's Warning - How terror, error and environmental disaster threaten humankind's future in this century-on Earth and beyond. New York: Basic Books, 2003.

57. DALY, H. Crescimento sustentável? Não, obrigado. Ponto de vista. In: Ambiente \& Sociedade. vol. 7, n. 2, Campinas, jul/dez. 2004. Disponível em: <http://dx.doi.org/10.1590/S1414753X2004000200012>. Acesso em: 25 jun. 2018. 